\title{
How does agonistic behaviour differ in albino and pigmented fish?
}

Ondřej Slavík, Pavel Horký, Marie Wackermannová

In addition to hypopigmentation of the skin and red iris colouration, albino animals also display distinct physiological and behavioural alterations. However, information on the social interactions of albino animals is rare and has mostly been limited to specially bred strains of albino rodents and animals from unique environments in caves. Differentiating between the effects of albinism and domestication on behaviour in rodents can be difficult, and social behaviour in cave fish changes according to species-specific adaptations to conditions of permanent darkness. The agonistic behaviours of albino offspring of pigmented parents have yet to be described. In this study, we observed agonistic behaviour in albino and pigmented juvenile Silurus glanis catfish. We found that the total number of aggressive interactions was lower in albinos than in pigmented catfish. The distance between conspecifics was also analysed, and albinos showed a tendency towards greater separation from their same-coloured conspecifics compared with pigmented catfish. These results demonstrate that albinism can be associated with lower aggressiveness and with reduced schooling behaviour preference, as demonstrated by a tendency towards greater separation of albinos from conspecifics. 


\section{How does agonistic behaviour differ in albino and pigmented fish?}

\section{Ondřej Slavík, ${ }^{1}$ Pavel Horký and Marie Wackermannová}

3 Department of Zoology and Fisheries, Faculty of Agrobiology, Food and Natural Resources, Czech

4 University of Life Sciences Prague, Kamýcká 129, Prague 6, Suchdol 165 21, Czech Republic

\section{Abstract}

6 In addition to hypopigmentation of the skin and red iris colouration, albino animals also display

7 distinct physiological and behavioural alterations. However, information on the social

8 interactions of albino animals is rare and has mostly been limited to specially bred strains of

9 albino rodents and animals from unique environments in caves. Differentiating between the

10 effects of albinism and domestication on behaviour in rodents can be difficult, and social

11 behaviour in cave fish changes according to species-specific adaptations to conditions of

12 permanent darkness. The agonistic behaviours of albino offspring of pigmented parents have yet

13 to be described. In this study, we observed agonistic behaviour in albino and pigmented juvenile

14 Silurus glanis catfish. We found that the total number of aggressive interactions was lower in

15 albinos than in pigmented catfish. The distance between conspecifics was also analysed, and

16 albinos showed a tendency towards greater separation from their same-coloured conspecifics

17 compared with pigmented catfish. These results demonstrate that albinism can be associated with

18 lower aggressiveness and with reduced schooling behaviour preference, as demonstrated by a

19 tendency towards greater separation of albinos from conspecifics.

20 Running title: Aggressive behaviour in catfish

\footnotetext{
${ }^{1}$ Corresponding author's e-mail address: oslavik@af.czu.cz
} 
Introduction

24 Albinism is generally the result of combinations of homozygous recessive mutations from 25 pigmented parents, and in particular, albinos are often unable to synthesize tyrosine and melatonin hormones (Carden et al., 1998). This disability is not only associated with red irises and light skin colouring (oculocutaneous albinism, OCA; Carden et al., 1998) but also with physiological, behavioural and social alterations. Some of vertebrate albinisms are indeed associated with increased levels of tyrosine and catecholamine accompanying with physiological and behavioural changes that occur during adaptation to specific conditions in caves (Bilandžija et al., 2013).

Information on the prevalence of terrestrial albino animals in the wild is primarily based on reports, and information on social interactions between albinos is mostly limited to studies of specially bred strains of albino rats, whose behaviour is strongly influenced by domestication

35 (Himmler et al., 2014). The eyes of albino rodents show reduced adaptation to light, often leading to photoreceptor degradation (Prusky et al., 2002; Refinetti, 2007; Marc et al., 2008), which in turn can cause loss of vision (Buhusi, Perera \& Meck, 2005) and movement perception (Hupfeld \& Hoffmann, 2006), eventually leading to acrophobia and/or photophobia (Abeelen \& Kroes, 1967; Owen, Thiessen \& Lindzey, 1970). Albino rodents have a poorer sense of smell 40 (Keeler, 1942) and display lower activity levels compared with pigmented conspecifics (Fuller, 1967; DeFries, 1969). In particular, their activity is low during the day and increases during the

42 night (Stryjek et al., 2013). Albino rats also spend longer periods in deep sleep (rapid eye 
43 movement, REM), especially during the dark phase (Benca, Gilliland \& Obermeyer, 1998), and

44 during the night, they sleep more often out of the nests relative to pigmented conspecifics

45 (Stryjek et al., 2013). Albino rats are slower to inhibit the fear response and explore new objects

46 (Pisula et al., 2012), and they are less effective in completing spatial tasks (Harker \& Whishaw,

47 2002). For example, albino rats displayed higher hoarding activity (Rebouças \& Schmidek,

48 1997), and they burrowed more slowly and constructed less complex systems of tunnels

49 compared with wild conspecifics (Stryjek, Modlińska \& Pisula, 2012).

Furthermore, albino vertebrates can be found in water environments, and compared with

51 pigmented conspecifics, they display physiological and behavioural differences. For example,

blind tetra Astyanax mexicanus (De Filippi 1853) living in caves (Jeffery, 2001), compared with

the pigmented surface-dwelling form, display physiological adaptations to permanent darkness

and limited food availability, such as greater number of taste buds (Yamamoto et al., 2009) and

highly sensitive sensors in the lateral line (Yoshizawa et al., 2010; 2013; 2014. Such

physiological adaptations appear to have resulted in a decrease in the length of sleep (Duboué,

57 Keene \& Borowsky, 2011), loss of shoaling behaviour (Kowalko et al., 2013), and an evolutionary shift from fighting to food source searching, leading to the loss of hierarchy dominance and aggressiveness (Elipot et al., 2013). On the contrary, blind albino catfish in caves displayed agonistic behaviour (Parzefall \& Trajano, 2010) likely reflecting their relatively large body size and bottom-dwelling form associated with stronger competition for resources. For example, the catfish Pimelodella kronei (Ribeiro 1907) showed a similar level of aggressiveness to its pigmented and sighted ancestor Pimelodella transitoria (Ribeiro 1907; Trajano, 1991). 
66 Slavík, Horký \& Maciak, (2015) described the separation of albino Silurus glanis (Linnaeus

67 1758) catfish from a group of pigmented conspecifics. Irregularity of albinos in a group of

68 pigmented conspecifics means a guiding target for predators (Landeau \& Terborgh, 1986;

69 Theodorakis, 1989), facilitating their hunting (Ellegren et al., 1997), and may be a reason for

70 exclusion of albinos from a group (Slavík, Horký \& Maciak, 2015). However, it is not yet clear

71 whether albinism in animals is associated with alternative social behaviour, resulting in for

72 example, ostracism. A possible alternative behavioural display is a shift in aggression altering

73 e.g. between domesticated albino rodents and their wild ancestors and/or between troglobites and

74 their pigmented surface-dwelling counterparts. In the present study, we observed aggressiveness

75 in albino and pigmented catfish Silurus glanis from surface waters. Considering the generally

76 lower level of aggression observed in albino animals, we assumed that agonistic behaviour

77 would be lower in albinos than in pigmented conspecifics.

\section{Materials \& Methods}

Albinism in catfish Silurus glanis L. 1758 has been commonly recorded in the wild (Dingerkus, Seret \& Guilbert, 1991), where catfish usually occur in groups (Boulêtreau et al., 2011). Only juvenile catfish were used to reflect the behaviour of wild fish. These juveniles were spatially separated from adults (Slavík et al., 2007), and showed complex social behaviours under the experimental conditions (Slavík, Maciak \& Horký, 2012; Slavík et al., 2016).

\section{Experimental animals}

The fish used in this experiment were hatchery-reared juvenile catfish. One shoal of pigmented and one shoal of albino catfish that were unfamiliar to each other were obtained from local fish suppliers (Czech Fishery Ltd., Rybářství Hluboká and Rybářství Třeboň, Czech Republic, 
88 respectively). A total of 400 approximately equally sized fish (200 from each shoal) were 89 transported from the hatcheries to the laboratory at 4 months of age. The fish were transported

90 under stable conditions in oxygenated tanks in an air-conditioned loading space. Transport lasted

91 approximately 2 hours, and there were no observable effects on the health or mortality of the 92 fish.

93 The fish were maintained in 2 separate holding tanks $\left(380 \mathrm{~L}\right.$ each, initial density $1.9 \mathrm{~kg} \mathrm{~m}^{-3}$; 94 one shoal or 200 individuals per tank) for 8 weeks prior to the start of the experiment. The fish 95 were fed food pellets ad libitum (Biomar Group, Denmark,www.biomar.com) that were 96 distributed throughout the entire tank, providing free access to food to all individuals twice a 97 day. The fish were maintaining under a natural photoperiod, which was the same regime they 98 had become accustomed to in the hatchery. The water was purified using biological filters with an integrated UV sterilizer (Pressure-Flo 5000, Rolf C. Hagen Inc., www.lagunaponds.com). The water temperature and dissolved oxygen were controlled automatically (HOBO data logger; Onset Computer Corporation, Bourne, Massachusetts, USA). Fish were measured (mean 103 $\mathrm{mm}$; range $90-117 \mathrm{~mm}$ ) and weighed (mean $10 \mathrm{~g}$, range $6-15 \mathrm{~g}$ ) at the end of the experiment and removed to separate tanks to prevent mixing with unused conspecifics.

All experimental fish (400 individuals) survived. After the experiment, the fish were released under the control of the Fish Management Authorities into fish ponds with extensive production 106 management.

\section{Experimental design}

The experiment was conducted in the laboratory between December 2013 and January 2014. A pair of randomly selected individuals of the same colour was placed into a rectangular plastic experimental arena (36 cm long, $18 \mathrm{~cm}$ wide, $20 \mathrm{~cm}$ high) at the beginning of each trial. The 
111 arena was separated by a partition into two equal parts, and the individuals were placed on

112 opposite sides of the arena. After an acclimation period of 1 minute, the partition was removed

113 and the behaviour of the fish was recorded for 5 minutes using a digital camera (GoPro Hero,

114 GoPro, Inc., San Matteo, CA, USA). The arena was flushed out and filled with clean water after 115 every trial. In total, 40 trials (20 pairs of albinos and 20 pairs of pigmented individuals) were 116 conducted.

\section{Data analysis}

118 In the laboratory experiment, we tested two levels of aggressive interactions among juvenile 119 catfish, designated as aggressive or mobile displays (Lehtonen, 2014). Aggressive displays were 120 further subdivided into frontal and lateral displays, and mobile displays were further subdivided 121 into chasing and biting displays (Hsu \& Wolf, 1999; Dijkstra et al., 2009). The sum of aggressive 122 interactions, referred to as 'total aggression,' was used in further analyses (Pauers et al., 2012).

123 The bottom of the experimental arena was divided into six equally sized squares $(9 \times 12 \mathrm{~cm})$ that 124 were used in the analyses of 'mutual distance.' Mutual distance was set as a three level class 125 variable. A mutual distance equal to 1 meant that the individuals were in the 'same zone,' 126 meaning that both conspecifics were in the same square. A mutual distance equal to 2 meant that 127 the individuals were in 'adjacent zones,' meaning that conspecifics were in adjacent squares. A 128 mutual distance equal to 3 meant that the individuals were in the 'farthest zones,' meaning that 129 there was one square between conspecifics. Variable 'size difference' was defined as the 130 difference between the weights of two interacting conspecifics in an experimental arena (mean $1311.9 \mathrm{~g}$; range $0-6 \mathrm{~g})$. For the purpose of analysing the probability of occurrence of different types 132 of agonistic behaviour over time, a 'time grid' of 5 seconds was set. For every time grid value, 133 the probability of occurrence of a particular agonistic behaviour was recorded as 1 (behaviour 
134 occurred) or 0 (behaviour did not occur). The EthoLog software program

135 (http://www.ip.usp.br/docentes/ebottoni/EthoLog/ethohome.html) was used to assign the number

136 of particular agonistic behaviours as well as the 'duration' (in seconds) that conspecifics spent at

137 particular mutual distances.

\section{Statistical analysis}

139 Statistical analyses were performed using the SAS software package (version 9.2; SAS Institute

140 Inc., Cary, NC, USA). When necessary, the data were square root transformed to meet normality

141 requirements.

142 Total aggression and duration were analysed using mixed models with random factors (PROC

143 GLIMMIX with Poisson distribution for total aggression and PROC MIXED with normal

144 distribution for duration). Random factors were used to account for repeated measures collected

145 for the same experimental units (pair of conspecifics) across the duration of the experiment. The

146 significance of each exploratory variable (i.e., fixed effects, including their interactions) in the

147 particular model was assessed using an F-test in which we sequentially dropped the least

148 significant effect, beginning with the full model (backward selection procedure). Least-squares

149 means (LSM), henceforth referred to as "adjusted means," were computed for class variables.

150 The differences between the classes were tested using a t-test, and a Tukey-Kramer adjustment

151 was used for multiple comparisons. The degrees of freedom were calculated using the Kenward-

152 Roger method (Kenward \& Roger, 1997).

153 The probabilities of occurrence for particular agonistic behaviours were analysed using the

154 generalized estimating equation (GEE) approach (Liang \& Zeger, 1986) for categorical, repeated

155 measurements using the GENMOD procedure with binomial distributions. This approach is an 
156 extension of generalized linear models that provides a semi-parametric approach to longitudinal

157 data analysis. In this study, four separate GENMOD procedures were designed to estimate the

158 probability of occurrence of particular agonistic behaviours (i.e., chasing, biting, frontal and

159 lateral displays) across the duration of the experiment.

\section{Ethics statement}

161 All of the laboratory experimental procedures were in compliance with valid legislative 162 regulations (law no. 246/1992, §19, art. 1, letter c). The permit was granted to O. Slavík, 163 according to Law no. 246/1992, §17, art. 1; permit no. CZ00167. All laboratory samplings were 164 conducted with the permission of the Departmental Expert Committee for Authorization of 165 Experimental Projects of the Ministry of Education, Youth and Sports of the Czech Republic 166 (permit no. MSMT-31220/2014-6). This study did not involve endangered or protected species.

\section{Results}

169

170

171

172

173

174

176

177

In total, we observed 1208 aggressive interactions, $68 \%$ of which were classified as lateral displays, $16 \%$ as frontal displays, $11 \%$ as chasing displays and $5 \%$ as biting. The total number of aggressive interactions was lower in the albino group $\left(\mathrm{F}_{1,110.6}=14.51, P<0.0002\right.$; Fig. 1). In addition, the probability of chasing $\left(\chi^{2}=6.64\right.$, d.f. $=2 ; P<0.0362$; Fig. 2a) and lateral display $\left(\chi^{2}=6.04\right.$, d.f. $=2 ; P<0.0488$; Fig. $\left.2 \mathrm{~b}\right)$ changed over time and differed between groups. In the albino group, the probability of chasing decreased over time, whereas the probability of lateral display did not show any significant trend. In the pigmented group, the probability of chasing also decreased over time, whereas the probability of lateral display sharply increased. In neither group did the probability of frontal display or biting vary significantly over time. The results 
178 indicated that albinos were less aggressive compared with their pigmented conspecifics, which

179 was primarily due to a higher probability of lateral display behaviours in the pigmented group.

180 Furthermore, the time that conspecifics spent at a particular distance from other conspecifics

181 varied in both groups $\left(\mathrm{F}_{5,111}=29.43, P<0.0001\right.$; Fig. 3$)$. While the catfish (both albino and

182 pigmented) generally spent the least amount of time in the farthest zones (time spent in the

183 farthest zones did not differ between albino and pigmented catfish), albinos spent more time in

184 adjacent zones and less time in the same zones than pigmented conspecifics (Adj. $P<0.05$ ).

185 Taken together, we found that albino catfish showed a higher tendency to be spatially separated

186 from conspecifics, whereas pigmented catfish showed a tendency towards close contact.

Discussion

The assumption that albinism is associated with different levels of aggression is supported by this study. In particular, our results support the theory that species with different levels of colouration should display different levels of aggression (Pryke \& Griffith, 2006) and that the level of aggression should correspond to different colour morphs (Pryke, 2009; Dijkstra et al., 2009). Indeed, one colour morph is often predicted to be more aggressive than others (Dijkstra et al., 2010). Our results are also consistent with recent findings showing that albinism has pleiotropic effects that are mediated through hormones that can affect both skin pigmentation and aggressive behaviour (Gonzales, Varizi \& Wilson, 1996; Ducrest, Keller \& Roulin, 2008). As reported by Horth (2003), increases in the aggression of the melanic form of mosquitofish correlate with changes in melanin synthesis. Therefore, albinism, in contrast to melanism, may be generally associated with lower aggression due to shared genetic control mechanisms. 
200 Comparison of the pigmented and albino forms of Silurus glanis revealed lower aggressiveness

201 in albinos. Loss of aggressive behaviour has been reported for albinos living in caves (Elipot et

202 al., 2013), and this relationship tend to be related to species-specific adaptations to unique

203 environmental conditions. For example, most of the populations of the blind albino tetra $A$.

204 mexicanus have lost aggressiveness, whereas individuals of the pigmented surface-dwelling form

205 blinded in an early ontogenetic stage remain aggressive at the same level as their sighted parents

206 (Espinasa, Yamamoto \& Jeffery, 2005). Blind albino catfish in caves displayed similar

207 aggressiveness to their sighted surface ancestors (Trajano, 1991). According to Espinasa,

208 Yamamoto \& Jeffery (2005), aggressive behaviour is activated by non-optical releasers, and the

209 reduction of aggressiveness is not the exclusive evolutionary pathway for blind albino

210 troglobites. Loss of vision in albino cavefish A. mexicanus is accompanied by the development

211 of non-visual sensors, such as neuromasts along the lateral line (Yoshizawa et al., 2010; 2013;

212 2014). Similarly, catfish are not typical visual predators such as salmonids (Valdimarsson \&

213 Metcalfe, 2001), but are adapted to prey detection in lowland rivers with a high level of turbidity,

214 where prey are often hunted during flash floods (Slavík et al., 2007). Six robust tactile bristles

215 are used for prey detection in these catfish, and with the aid of highly sensitive lateral line, the

216 species can detect hydrodynamic traces as long as 10 seconds after the passage of prey

217 (Pohlmann, Grasso \& Breithaupt, 2001). Provided that the vision of pigmented catfish does not

218 represent the main tool for prey detection, it can be inferred that its role in the aggressive

219 behaviour of albino catfish S. glanis is also minor. Although it can be assumed that albino catfish

220 from surface waters are able to see, their vision may be impaired. Accordingly, albinism in mice

221 has been correlated with acrophobia, photophobia and lower visual acuity (Owen, Thiessen \&

222 Lindzey, 1970; Prusky et al., 2002; Buhusi, Perera \& Meck, 2005). Moreover, specially bred 
223 strains of albino rats (Sprague-Dawley) displayed a higher probability of playful attacks

224 compared with wild-type pigmented strains (Himmler et al., 2014). The behaviour of this

225 Sprague-Dawley strain, however, was also different from other albino strains. Interestingly, the

226 authors attributed these differences to differing levels of domestication in each of the strains.

227 Playful attacks are associated not only with domestication (see review Himmler et al., 2014) but

228 also with reduced aggression, as albino rats are less aggressive than their wild-type pigmented

229 counterparts (Barnett, Dickson \& Hocking, 1979; Barnett, 1981). Although a direct comparison

230 between aggressiveness in catfish and rats is not possible, we speculate that albinism may be

231 generally associated with lower aggression compared with normally pigmented conspecifics.

232 Aggression is also associated with social position or rank (Mazur \& Booth, 1998; Staffan,

233 Magnhagen \& Alanärä, 2002). For example, an albino female vampire bat Desmondus rotundus

234 bred with pigmented individuals hold the lowest social position (Uieda, 2001). Hence, albinism

235 may be associated with not only lower aggressiveness but also lower dominance, as these

236 characteristics are often correlated (Dijkstra, Seehausen \& Groothuis, 2005; Pryke \& Griffith,

237 2006). Indeed, consistent with this idea, ostracism of albino catfish by a group of pigmented

238 conspecifics has been described (Slavík, Horký \& Maciak, 2015), and the low ability of albinos

239 to remain within a group may be another reason for the high predation risk in albinos (Ellegren et

240 al., 1997).

241 Albino catfish also showed a greater tendency towards spatial separation compared with their

242 pigmented conspecifics, which preferred to be nearer to one another. This finding differs from

243 what was observed in domesticated albino rats, which were found to be more tolerant of

244 conspecifics compared with wild-type strains (Himmler et al., 2013; 2014). Indeed, colour-

245 assortative shoaling is often observed (McRobert \& Bradner, 1998; Spence \& Smith, 2006; 
246 Goméz-Laplaza, 2009; Rodgers, Kelley \& Morell, 2010). Considering the fact that albino catfish

247 are unable to darken their body colour to avoid aggressive interactions with dominant

248 conspecifics (O’Connor, Metcalfe \& Taylor, 1999; Höglund, Balm \& Winberg, 2000), spatial

249 separation may be a strategy for avoiding the escalation of aggressive behaviours. On the other

250 hand, if albino catfish have poor vision, then their low tendency towards grouping may be a

251 result of this weakened physiological condition. Accordingly, blind cave fish displayed loss of

252 schooling behaviour (Parzefall \&Trajano, 2010; Kowalko et al., 2013). In the case of troglobites,

253 however, a low tendency towards grouping is considered to represent an evolutionary adaptation

254 to sparse prey and low food availability, conditions where life in a group is not beneficial to

255 better foraging activity such as it is in surface waters (Griffith et al., 2004; Ward \& Hart, 2005).

256 Large numbers of albinos existing together in the wild has only been reported in insects (Hoste et

257 al., 2003), and whether albinos are mutually attracted to each other and form larger groups in

258 nature remains unknown.

\section{Conclusions}

261 Similarities to the shift in the behaviour of albino catfish towards lower aggressiveness can be

262 found in domesticated albino rodents and their wild pigmented counterparts as well as between

263 blind cave fish and their sighted ancestors from surface waters. Therefore, loss of pigmentation

264 may not only be linked to aggression in albinos, but also have other pleiotropic effects that can

265 be observed, for example, as impaired eyesight in surface environments and/or specie-specific

266 evolutionary adaptations to conditions of permanent darkness. In addition, albinos were found to 
267 maintain greater distances between themselves compared with pigmented individuals in the

268 present study, corresponding to the loss of schooling behaviour in blind cave fish.

269

270 Acknowledgements

271 The authors sincerely thank Sergio Pellis, Tobias Backström and the anonymous referee for

272 critical evaluation and valuable comments on the manuscript. In addition, the authors wish to 273 thank A. Slavikova for the help with earlier versions of the manuscript.

References

276

277

278

279

280

281

282

283

284

285

286

Abeelen van JHF, Kroes WH. 1967. Albinism and mouse behaviour. Genetica 38:419-429.

Barnett SA, Hocking WE. 1981. Further experiments on the social interactions of domestic „Norway“ rats. Aggressive Behavior 7:259-263.

Barnett S A, Dickson RG, Hocking WE. 1979. Genotype and environment in the social interactions of wild and domestic „Norway“ rats. Aggressive Behaviour 5:105-119.

Benca RM, Gilliland MA, Obermeyer WH. 1998. Effects of lighting conditions on sleep and wakefulness in albino Lewis and pigmented Brown Norway rats. Sleep 21:451-460.

Bilandžija H, Ma L; Parkhurst A, Jeffery WR. 2013. A potential benefit of albinism in Astyanax cavefish: Downregulation of the oca2 gene increases tyrosine and catecholamine levels as an alternative to melanin synthesis. PloS ONE 8: e80823. DOI: 10.1371/journal.pone.0080823 
287

288

289

290

291

292

293

294

295

296

297

298

299

300

301

302

303

304

305

306

307

Boulêtreau S, Cucherousset J, Villéger S, Masson R, Santoul F. 2011. Colossal aggregations of giant alien freshwater fish as a potential biogeochemical hotspot. PLOS ONE 6: e25732.

Britton JR, Davies GD. 2006. First record of the white catfish Ameiurus catus in Great Britain. Journal of Fish Biology 69: 1236-1238, DOI: 10.1111/j.1095-8649.2006.01171.x

Buhusi CV, Perera D, Meck WH. 2005. Memory for timing and auditory signals in albino and pigmented rats. Journal of Experimental Psychology - Animal Behaviour 31:18-30, DOI: 10.1037/0097-7403.31.1.18

Carden SM, Boissy RE, Schoettker PJ, Good WV. 1998. Albinism: modern molecular diagnosis. British Journal of Ophthalmology 82:189-1995.

DeFries JC. 1969. Pleiotropic effects of albinism on open field behaviour in mice. Nature 221:65-66.

Dijkstra PD, Seehausen O, Groothuis TGG. 2005. Direct male-male competition can facilitate invasion of new colour types in Lake Victoria cichlids. Behaviour Ecology and Sociobiology 58:136-143, DOI: 10.1007/s00265-005-0919-5

Dijkstra PD, Hemelrijk CK, Seehausen O, Groothius TGG. 2009. Colour polymorphism reduces intrasexual selection in assemblages of cichlid fish. Behaviour Ecology 20:138144.

Dijkstra PD, Lindström J, Metcalfe NB, Hemelrijk CK, Brendel M, Seehausen O, Groothius TGG. 2010. Frequency-dependent social dominance in a color polymorphic cichlid fish. Evolution 64:2797-2807, DOI: 10.1111/j.1558-5646.2010.01046.x 
308

309

310

311

312

313

314

315

316

317

318

319

320

321

322

323

324

325

326

327

328

Dingerkus G, Seret B, Guilbert E. 1991. The first albino wels, Silurus glanis Linnaeus, 1758, from France, with a review of albinism in catfishes (Teleostei: Siluriformes). Cybium 15:185-188.

Duboué ER, Keene AC, Borowsky RL. 2011. Evolutionary convergence on sleep loss in cavefish populations. Current Biology 21: 671-676. DOI: 10.1016/j.cub.2011.03020

Ducrest A-L, Keller L, Roulin A. 2008. Pleiotropy in the melanocortin system, coloration and behavioural syndromes. Trends in Ecology and Evolution 23:502-510.

Ellegren H, Lindgren G, Primmer RC, Møller PA. 1997. Fitness loss and germline mutations in barn swallows breeding in Chernobyl. Nature 389: 593-596.

Elipot Y, Hinaux H, Callebert J, Rétaux S. 2013. Evolutionary shift from fighting to foraging in blind cavefish through changes in the serotonin network. Current Biology 23: 1-10, DOI: $10.1016 /$ j.cub.2012.10.044

Espinasa L, Yamamoto Y, Jeffery RW. 2005. Non-optical releasers for aggressive behaviour in blind and blinded Astyanax (Teleostei, Characidae). Behavioural Processes 70: 144148, DOI:10.1016/j.beproc.2005.06.003

Fuller LJ. 1967. Effects of the albino gene upon behaviour of mice. Animal Behaviour 15:467470. http//dx.doi.org./10.1016/0003-3472(67)90045-0

Goméz-Laplaza ML. 2009. Recent social environment affects colour-assortative shoaling in juvenile angelfish (Pterophyllum scalare). Behavioural Processes 82:39-44.

Gonzales MI, Varizi S, Wilson CA. 1996. Behavioural effects of a $-\mathrm{MSH}$ and $\mathrm{MCH}$ after central administration in female rat. Peptides 17:171-177. 
Griffith SW, Brockmark S, Höjesjö J, Johnsson IJ. 2004. Coping with divided attention: the advantage of familiarity. Proceedings of the Royal Society of London B 271: 695699.Harker KT, Whishaw IQ. 2002. Place and matching-to-place spatial learning affected by rat inbreeding (Dark-Agouti, Fischer 344) and albinism (Wistar, SpragueDawley) but no domestication (wild rat vs. Long-Evans, Fischer-Norway). Behavioural Brain Resources 134:467-477.

Harker KT, Whishaw IQ. 2002. Place and matching-to-place spatial learning affected by rat inbreeding (Dark-Agouti, Fischer 344) and albinism (Wistar, Sprague-Dawley) but no domestication (wild rat vs. Long-Evans, Fischer-Norway). Behavioural Brain Resources 134:467-477.

Himmler BT, Derksen SM, Stryjek R, Modlinska K, Pisula W, Pellis SM. 2013. How domestication modulates play behaviour: a comparative analysis between wild rats and a laboratory strain of Ratus norvegicus. Journal of Comparative Psychology 127:453-464.

Himmler, SM, Modlinska K, Stryjek R, Himmler BT, Pisula W, Pellis SM. 2014. Domestication and diversification: a comparative analysis of the play fighting of the Brown Norway, Sprague-Dawley, and Wistar Laboratory strains of (Rattus norvegicus). Journal of Comparative Psychology, DOI:10.1037/a0036104.

Höglund E, Balm PHM, Winberg S. 2000. Skin darkening a potential social signal in subordinate Arctic charr (Salvenius alpinus): the regulatory role of brain monoamines and pro-opiomelanocorticon-derived peptides. Journal of Experimental Biology 203:17111721. 
350 Horth L. 2003. Melanic body-color and aggressive mating behaviour are correlated traits in 351 male mosquitofish, (Gambusia holbrooki). Proceedings of the Royal Society of London Series B 270:1033-1040.

Hoste B, Simpson SJ, DeLoof A, Breuer M. 2003. Behavioural differences in Locusta migratoria associated with albinism and their relation to [His $\left.{ }^{7}\right]$-corazonin. Physiology \& Entomology 28:32-38.

Hsu Y, Wolf LL. 1999. The winner and looser effect: integrating multiple experiences. Animal Behaviour 57:903-910.

Hupfeld D, Hoffmann K-P. 2006. Motion perception in rats (Rattus norvegicus sp.): deficits in albino Wistar rats compared to pigmented Long-Evans rats. Behavioural Brain Resources 170:29-33, DOI: 10.1016/j.bbr.2006.01.022

Jeffery RW. 2001. Cavefish as a model system in evolutionary developmental biology. Developmental Biology 291: 1-12.

Keeler CA. 1942. The association of the black (non-agouti) gene with behaviour in the Norway rat. Journal of Heredity 33:371-384.

Kenward MG, Roger JH. 1997. Small sample inference for fixed effects from restricted maximum likelihood. Biometrics 53:983-997.

Kowalko EJ, Rohner N, Rompani BS, Peterson KB, Weber J, Hoekstra EH, Jeffery RW, Borowsky R, Tabin JC. 2013. Loss of schooling behaviour in cavefish through sightdependent and sight-independent mechanism. Current Biology 23: 1874-1883, doi: 10.1016/j.cub.2013.07.056 
371 Landeau L, Terborgh J. 1986. Oddity and the 'confusion effect' in predation. Animal Behaviour 34: 1372-1380.

373

374

375

376

377

378

379

380

381

382

383

384

385

386

387

388

389

390

391

Leal ME, Schulz UH, Albornoz PL, Machado R, Ott PH. 2013. First Record of Partial Albinism in two Catfish Species of Genidens (Siluriformes: Ariidae) in an Estuary of Southern Brazil. Brazilian Archives of Biology and Technology 56: 237-240.

Lehtonen TK. 2014. Colour biases in territorial aggression in a Neotropical cichlid fish. Oecologia 175: 85-93, DOI: 10.1007/s00442-013-2879-1

Liang KY, Zeger SL. 1986. Longitudinal data analysis using generalized linear models. Biometrika 73:13-22.

Marc RE, Jones BW, Watt CB, Vazquez-Chona F, Vaughan DK. 2008. Extreme retinal remodelling triggered, by light damage: implications for age related macular degeneration. Molecular Vision 14:782-806.

Mazur A, Booth A. 1998. Testosterone and dominance in men. Behavioural Brain. Science 21:353-397.

McRobert PS, Bradner J. 1998. The influence of body coloration on shoaling preference in fish. Animal Behaviour 56:611-615.

O’Connor KL, Metcalfe NB, Taylor AC. 1999. Does darkening signal submission in territorial contest between juvenile Atlantic salmon, Salmo salar? Animal Behaviour 58:12691276.

Owen K, Thiessen DD, Lindzey G. 1970. Acrophobic and photophobic responses associated with the albino locus in mice. Behavior Genetics 1:249-255. 
392 Parzefall J, Trajano E. 2010. Behavioral Patterns in Subterranean Fishes. pp 81-114, In:

393 Trajano E, Bichuette ME, Kapoor BG (Eds.) Biology of Subterranean Fishes. Science 394 Publishers, Enfield, NH.

395 Pauers MJ, Kapfer JM, Doehler K, Lee TJ, Berg CS. 2012. Gross colour pattern is used to 396 distinguish between opponents during aggressive encounters in a Lake Malawi cichlid. 397 398 Ecology of Freshwater Fish 21:34-41, DOI: 10.1111/j.1600-0633.2011.00520.x

Pisula W, Turlejski K, Stryjek R, Nalęcy-Tolak A, Grabiec M, Djavadian RL. 2012. Response to novelty in the laboratory Wistar rat wild-captive WWCPS rat, and the grey short-tailed opossum (Monodelphis domestica). Behavioural Processes 91:145-151.

401

402

403

404

405

406

407

408

409

410

411

412

413

Pohlmann K, Grasso FW, Breithaupt T. 2001. Tracking wakes: the nocturnal predatory strategy of piscivorous catfish. Proceedings of the National Academy of Sciences of the United States of America 98: 7371-7374.

Prusky GT, Harker KT, Douglas MR, Whishaw IQ. 2002. Variation in visual acuity within pigmented, and between pigmented and albino rat strains. Behavioural Brain Research 136:339-348.

Pryke SR. 2009. Is red an innate or learned signal of aggression and intimidation? Animal Behaviour 78:393-398, DOI: 10.1016/j.anbehav.2009.05.013

Pryke SR, Griffith SC. 2006. Red dominants black: agonistic signalling among head morphs in the colour polymorphic Gouldina finch. Proceedings of the Royal Society of London Series B 273:949-957, DOI: 10.1098/rspb.2005.3362.

Rebouças RCR, Schmidek RW. 1997. Handling and isolation in three strains of rats affect open field, exploration, hoarding and predation. Physiology \& Behaviour 62:1159-1164. 
414 Refinetti R. 2007. Enhanced circadian photoresponsiveness after prolonged dark adaptation in 415 seven species of diurnal and nocturnal rodents. Physiology \& Behaviour 90:431-437.

416

417

418

419

420

421

422

423

424

425

426

427

428

429

430

431

432

433

434

435

Rodgers MG, Kelley LJ, Morell JL. 2010. Colour change and assortment in the western rainbowfish. Animal Behaviour 79:1025-1030, DOI: 10.1016/j.anbehav.2010.01.017

Slavík O, Horký P, Bartoš L, Kolářová J, Randák T. 2007. Diurnal and seasonal behaviour of adult and juvenile European catfish as determined by radio-telemetry in the River Berounka, Czech Republic. Journal of Fish Biology 71:104-114.

Slavík O, Maciak M, Horký P. 2012. Shelter use of familiar and unfamiliar groups of juvenile European catfish Silurus glanis. Applied Animal Behaviour Science 142:116-123.

Slavík O, Horký P, Maciak M. 2015. Ostracism of an albino individual by a group of pigmented catfish. PLoS ONE, DOI:10.1371/journal.pone.0128279

Slavík O, Horký P, Maciak M, Wackermannová M. 2016. Familiarity, prior residency, resource availability and body mass as predictors of the movement activity of the European catfish. Journal of Ethology 34: 23-30, DOI 10.1007/s10164-015-0441-9

Spence R, Smith C. 2006. The role of early learning in determining shoaling preferences based on visual cues in the Zebrafish, Danio rerio. Ethology 113:62-67, DOI: 10.1111/j.14390310.2006.01295.x

Staffan F, Magnhagen C, Alanärä A. 2002. Variation in food intake within groups of juvenile perch. Journal of Fish Biology 60:606-614.

Stryjek R, Modlińska K, Pisula W. 2012. Species specific behavioural patterns (digging and swimming) and reaction to novel objects in wild type, Wistar, Sprague-Dawley and Brown Norway rats. PLoS ONE 7:e40642, DOI: 10.1371/journal.pone.0040642 
436 Stryjek R, Modlińska K, Turlejski K, Pisula W. 2013. Circadian rhythm of outside-nest

437

438

439

440

441

442

443

444

445

446

447

448

449

450

451

452

453

454

455

456

activity in wild (WWCPS), albino and pigmented laboratory rats. PloS ONE 8: e66055.doi:101371/journal pone.0066055

Theodorakis $\mathrm{ChW}$, 1989. Size segregation and effects of oddity on predation risk in minnow schools. Animal Behaviour 38: 496-502.

Trajano E. 1991. The agonistic behaviour of Pimelodella kronei, a troglobitic catfish from Southeastern Brazil (Siluriformes, Pimelodidae). Behavioural Processes 23:113-124.

Uieda W. 2001. Behavior of an albino vampire bat, Desmondus rotundus (E. Geoffroy) (Chiroptera, Phyllostomatideae), in captivity. Revista Brasiliera de Zoologica 18:641644. http://dx.doi.org./10.1590/S0101-81752001000200031

Valdimarsson SK, Metcalfe NB. 2001. Is the level of aggression and dispersion in territorial fish dependent on light intensity? Animal Behaviour 61:1143-1149, DOI: 10.1006/anbe.2001.1071

Wakida-Kusunoki AT, Amador-del-Angel LE. 2013. First record of albinism in gafftopsail catfish Barge marinus (Pisces: Ariidae) from southeast Mexico. Revista de Biologia Marina Y Oceanografia 48: 203-206.

Ward AJW, Hart P JB. 2005. Foraging benefits of shoaling with familiars may be exploited by outsiders. Animal Behaviour 69: 329-335.

Yamamoto Y, Byerly MS, Jackman WR, Jeffery WR. 2009. Pleiotropic function of embryonic sonic hedgehog expression link jaw and taste bud amplification with eye loss during cavefish evolution. Developmental Biology 330:200-211 
457 Yoshizawa M, Gorički Š, Soares D, Jeffery RW. 2010. Evolution of a behavioural shift 458 mediated by superficial neuromasts helps cavefish find food in darkness. Current Biology 20: 1631-1636 doi: 10.1016/j.cub.2010:07.017

460

461

462

463

464

465

466

467

468

469

470

471

472

473

474

475

476

477

Yoshizawa M, O'Quin EK, Jeffery RW. 2013. Evolution of an adaptive behaviour and its sensory receptors promotes eye regression in blind cavefish: response to Borowsky (2013). BMS Biology 11:82.

Yoshizawa M, Jeffery RW, Netten van MS, McHenry JM. 2014. The sensitivity of lateral line receptors and their role in the behaviour of Mexican blind cavefish (Astyanax mexicanus). Journal of Experimental Biology 217:886-895 DOI: 10.1242jet.094599

\section{Figure legends}

Fig. 1: Total number of aggressive interactions (adjusted means \pm SE) across albino and pigmented treatments. Significant differences are indicated (*; Tukey-Kramer adjusted $\mathrm{P}<0 \cdot 0002)$.

Fig. 2: Probability of chasing (a) and lateral display (b) as a function of time across the two treatments. Dotted line = albino catfish; black line = pigmented catfish.

Fig. 3: Duration (adjusted means $\pm \mathrm{SE}$ of square root data) of time that conspecifics spent at particular mutual distances across albino and pigmented treatments. Significant differences are indicated (*; Tukey-Kramer adjusted $\mathrm{P}<0 \cdot 05)$. 
1

Total number of aggressive interactions (adjusted means \pm SE) across albino and pigmented treatments.

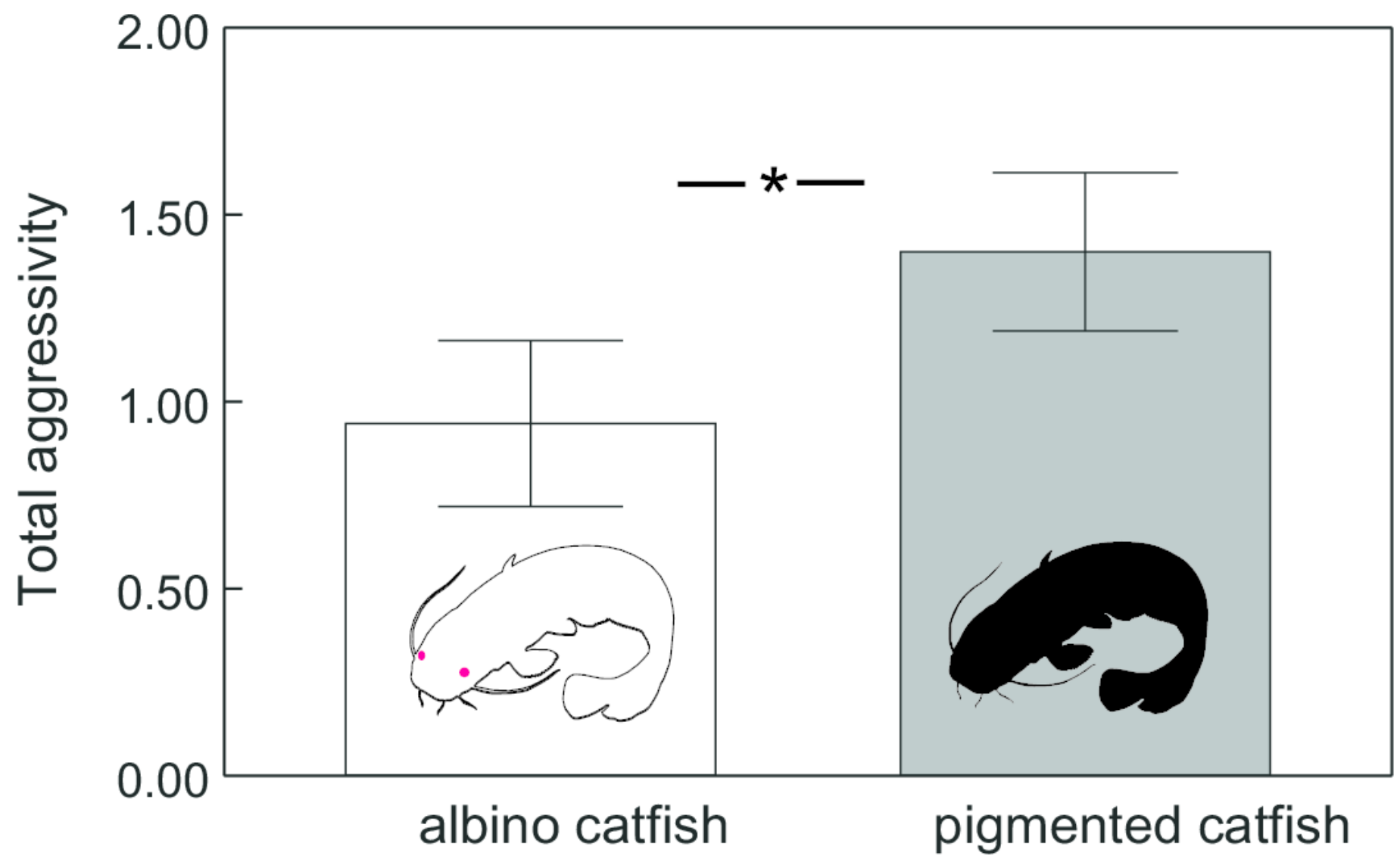


2

Probability of chasing (a) and lateral display (b) as a function of time across the two treatments.

Dotted line $=$ albino catfish; black line $=$ pigmented catfish .

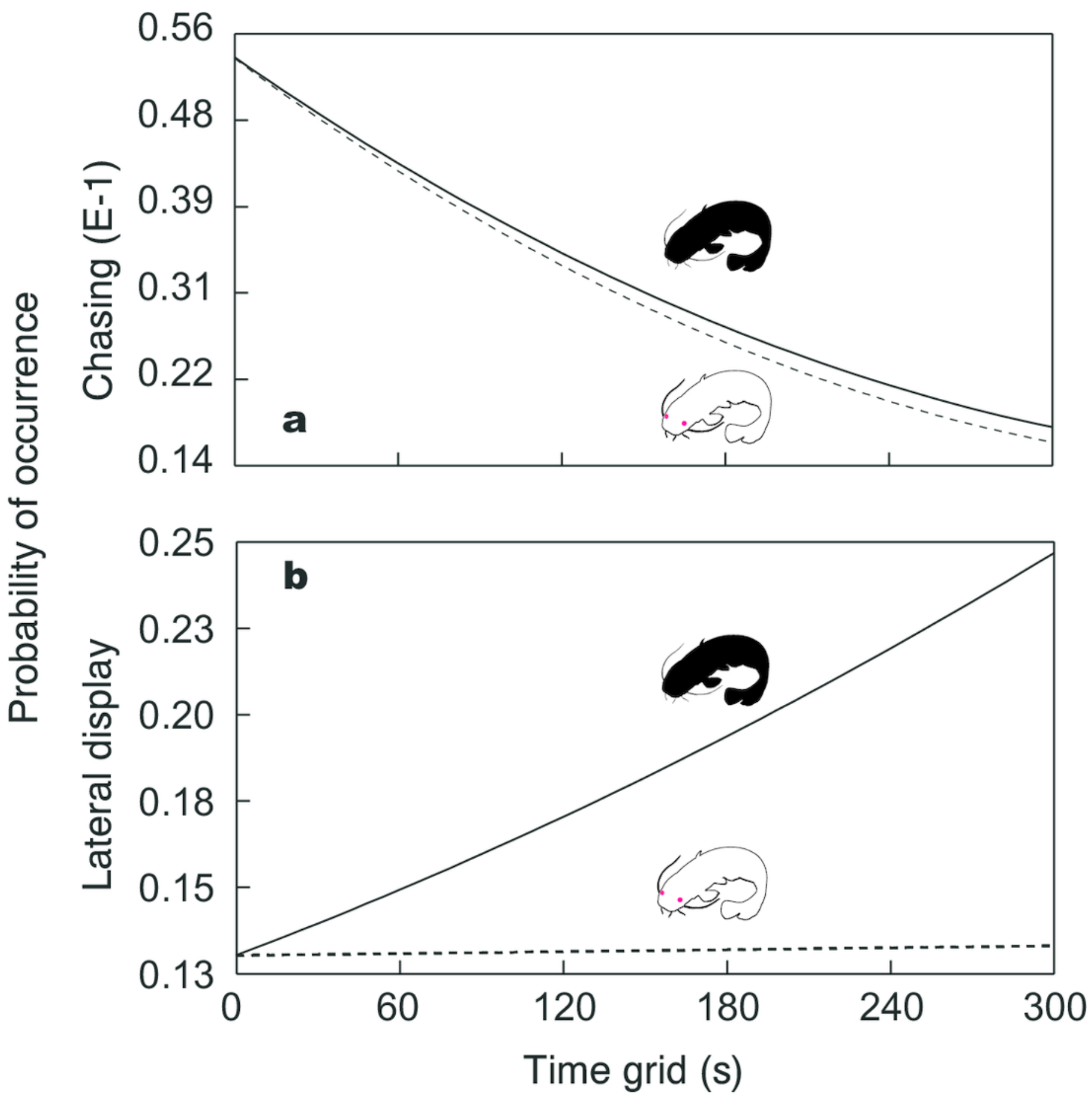


3

Duration (adjusted means \pm SE of square root data) of time that conspecifics spent at particular mutual distances across albino and pigmented treatments.

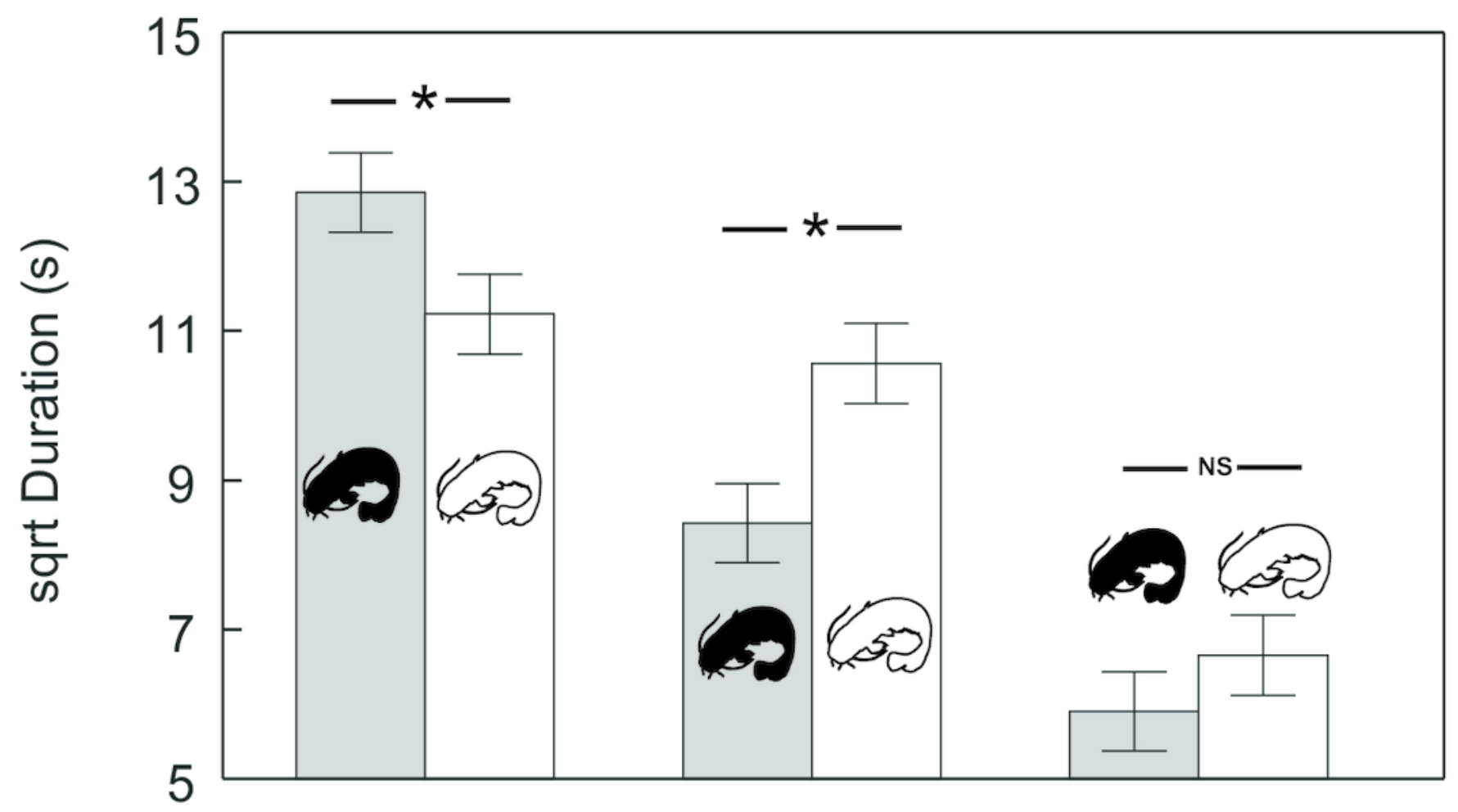

same square adjacent square separated by a square 